\title{
DGA Method Implementation for Incipient Fault Analysis using Gas Concentrations
}

\author{
Jyoti Singh \\ M Tech Scholar \\ Rabindranath Tagore University \\ Bhopal, M.P, India \\ jyodce151@gmail.com
}

\author{
Dr. Prateek Nigam \\ HOD \\ Rabindranath Tagore University \\ Bhopal, M.P, India \\ prateek.nigam@aisectuniversity.ac.in
}

\author{
Achie Malviya. \\ Assistant Professor \\ Rabindranath Tagore University \\ Bhopal M. P , India \\ achie.malviya@aisectuniversity.ac.in
}

\begin{abstract}
Power transformers are essential devices for the durable and reliable performance of an electrical system. the main objective of this study is to analyze three classical diagnosis techniques to identify incipient faults in Transformer oil using Rogers's Ratio Method, Doernenburg Ratio Method, and ANN which is a type of artificial intelligence learning method. Implementation of the system in MATLAB software for each diagnosis method and compare their accuracy and efficiency and hence design three diagnosis methods of DGA for condition assessment of Power Transformer. And the analysis on the MATLAB software shall be carried so as to detect the best method for detection of a certain type of fault and the best suited method for overall fault analysis for a certain data sets out of the three methods. This technique utilizes the learning capacity of that artificial neural network has been shown to be more efficient in detecting different mistakes. The overall error detection accuracy of such gas neural network study was found to be 73.8 percent.
\end{abstract}

Keywords: DGA, ANN, KDD, DST.

\section{INTRODUCTION}

Power transformers are essential devices for the durable and reliable performance of an electrical system. Their continuity is therefore the daily activity of the energy suppliers. Consequently, their proper maintenance based on detected incipient failures and/or degraded conditions is essential to achieve this goal. When failures occur in a transformer, planning for subsequent maintenance is of the utmost importance; otherwise, malfunctions will occur which could lead to system failure.

Even under typical operating circumstances, a lengthy transformer produces gas. Nevertheless, it is subjected to electronics, physical, biochemical, and thermally pressures on a routine basis throughout time, resulting in a significant degree of gas generation in the transformers insulating system [1]. The gas concentration, on either hand, will rise if there is any abnormality. Whenever oil decomposes, gases such as hydrogen
$\left(\mathrm{H}_{2}\right)$, methane $\left(\mathrm{CH}_{4}\right)$, acetylene $\left(\mathrm{C}_{2} \mathrm{H}_{2}\right)$, ethylene $\left(\mathrm{C}_{2} \mathrm{H}_{4}\right)$, and ethane $\left(\mathrm{C}_{2} \mathrm{H}_{6}\right)$ are generated, while when cellulose breaks down, methane $(\mathrm{CH} 4)$ and hydrogen $\left(\mathrm{H}_{2}\right)$ are formed. Carbon monoxide $(\mathrm{CO})$ and carbon dioxide $\left(\mathrm{CO}_{2}\right)$ are two gases that may be found in the atmosphere $\left(\mathrm{CO}_{2}\right)$. Carbon monoxide $(\mathrm{CO})$ and carbon dioxide $\left(\mathrm{CO}_{2}\right)$ imply problem caused by decay of the article, ethylene $\left(\mathrm{C}_{2} \mathrm{H}_{4}\right)$ and ethane $\left(\mathrm{C}_{2} \mathrm{H}_{6}\right)$ indicate an increase in fuel temperature, incomplete discharges (which supply hydrogen $\left(\mathrm{H}_{2}\right)$ and methane $\left(\mathrm{CH}_{4}\right)$ at low energy), and the arc can be confirmed by the release of acetylene $\left(\mathrm{C}_{2} \mathrm{H}_{2}\right)$ and hydrogen $\left(\mathrm{H}_{2}\right)$ [2][4].

\section{LITERATURE REVIEW}

S. S. M. Ghoneim et al. [1] The article proposes a novel technique using DGA technology to resolve the issue that occurs in conventional transformer failure diagnostic methods. The new method depends on an examination of 386 sets of data including dissolve gasses samples obtained from the Electricity Supply Chemical Laboratory of Egypt, as well as information by reputable bibliographic sources. Those datasets are utilized to construct the technical models as well as a test dataset to evaluate the method's correctness.

T. Kari, et al. [2] The Integrated Adaptive Neuro-Fuzzy Inference System (ANFIS) as well as the Dempster-Shafer theory (DST) are used in the article to propose a novel DGA technique for initial power transformer failure detection. To create new ANFIS-based fault diagnostic techniques, 4 of the 7 most common traditional techniques were researched, analyzed, and evaluated for improved accuracy and consistency. Improved DST is developed to combine the outcomes of each ANFIS-based model and offer complete as well as convincing fault diagnosis findings, to enhance fault detection performance and fault decision-making as trustworthy and fair.

M. Arshad et al. [3] Insulation system deterioration is a complicated physical process where many variables operate 
concurrently, making interpretation very challenging. In transformer with a lifetime that is nearer to the design, the insulation reacts extremely effectively. So when state of the current unit has now been adequately evaluated, strategic maintenance and operating methods are best developed. To simplify asset management and decision - making process, it is critical to assess the state of assets using effective and nonintrusive diagnosis and monitoring technologies, and an expert system.

O. E. Gouda et al. [4] This article introduces Dissolved Gas Analysis (DGA), which is a standard technique for detecting and diagnosing impending failures in power transformers. Many DGA-based methods have been proposed such as Duval Triangle, IEC, Roger's Ratio, Key Gases, etc. The relationship between gas and defect type is difficult to model and highly nonlinear. Knowledge from data discovery (KDD) based on raw set theory (RTD) can be used to find this relationship. The extracted and reduced rules are used to diagnose impending power transformer failures. The resulting rules have an accuracy of $81.25 \%$.

\section{OBJECTIVE}

- Analyze three classical diagnosis techniques to identify incipient faults in Transformer oil using Rogers's Ratio Method, Doernenburg Ratio Method and ANN which is a type of artificial intelligence learning method.

- Implementation of the system in MATLAB software for each diagnosis method and compare their accuracy and efficiency and hence design three diagnosis methods of DGA for condition assessment of Power Transformer.

- The analysis on the MATLAB software shall be carried so as to detect the best method for detection of certain type of fault and the best suited method for overall fault analysis for a certain data sets out of the three methods.

\section{Methodology}

This section mainly discusses DGA interpretation techniques such as Rogers Ratio, ANN, and Dornenburgs Ratio methods and their code representation for each method and flowchart representation to develop MATLAB programs for each diagnostic technique. The dissolved gas analysis (DGA) approach is based on the concentration of dissolved gases in the insulating oil and the specific limits of dissolved gas ratios. Some gas ratio limits and rules have been developed to specify transformer failures. These gas rules and ratios are assumed to be based on five main fuel gases: hydrogen $\left(\mathrm{H}_{2}\right)$, methane $\left(\mathrm{CH}_{4}\right)$, ethane $\left(\mathrm{C}_{2} \mathrm{H}_{6}\right)$, ethylene $\left(\mathrm{C}_{2} \mathrm{H}_{4}\right)$ and acetylene $\left(\mathrm{C}_{2} \mathrm{H}_{2}\right)$. In some interpretation techniques, carbon monoxide $(\mathrm{CO})$ has been added to these gases. Some non-flammable gases such as carbon dioxide $\left(\mathrm{CO}_{2}\right)$, nitrogen $\left(\mathrm{N}_{2}\right)$ and oxygen $\left(\mathrm{O}_{2}\right)$ have been developed in the event of a malfunction, but have no influence on fault diagnosis.

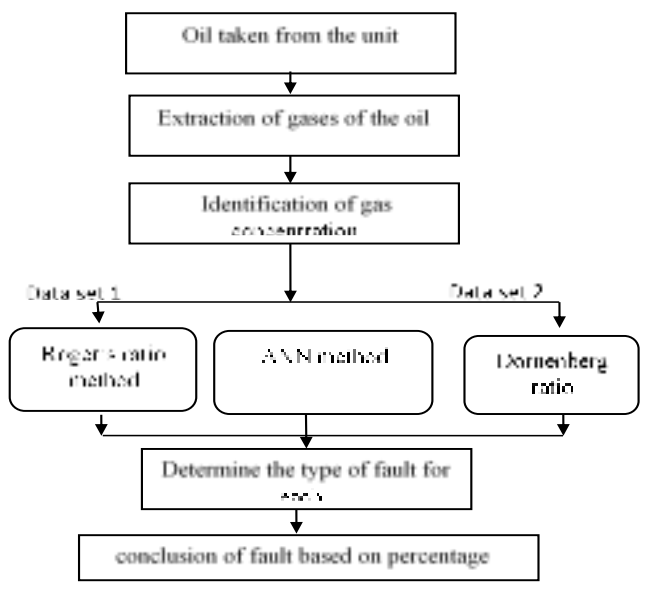

Fig. 1: Block diagram of Combined Dissolved Gas Analysis (DGA) Method

Figure 1 explains the error found by all the traditional methods examined during the work (artificial neural network (ANN), IEC, Doernenburg ratio and Rogers ratio. After the extraction of the dissolved gases from the mineral oil, the gas concentration For volume Several methods have been proposed to find dissolved gases, but among them the direct injection technique and the headspace method are the most accurate methods and directly provides the dissolved gas volume by injecting mineral oil, by entering the gas concentration in ppm (parts per million) for each diagnostic method there is the type of incipient error, the next step is to compare all types of incipient errors after each method and finally the conclusion will give the final unit error ( mineral oil) according to the percentage given by each method.

The main reason for combining three methods is: "None of the methods provide all kinds of examples. Reporting processes have high thermal, partial, and arc discharges, but no combination of thermal and electrical failures.

The severity of the transformer fault has been divided into three types based on the level of danger it presents, namely low, high and medium severity of the fault. The contribution of the total dissolved burnt gas during the analysis was immense when examining the state of the transformer. These two states (1) gravity, (2) total dissolved combustible gases (TDCG) were used throughout the study. For example, if the rate of change of TDCG> $30 \mathrm{ppm}$, this is considered a high severity thermal failure (T3). To achieve maximum inclusion in the work, the framework uses 9 gas concentration ratios, namely $\mathrm{H}_{2}, \mathrm{CH}_{4}$, $\mathrm{C}_{2} \mathrm{H}_{6}, \mathrm{C}_{2} \mathrm{H}_{2}, \mathrm{C}_{2} \mathrm{H}_{4}, \mathrm{CO}, \mathrm{CO}_{2}, \mathrm{~N}_{2}$ and $\mathrm{O}_{2}$. When parsing different methods, any entries with a missing value are represented by -1 
during parsing. The program takes the inputs required for each method and ignores the unnecessary ones. The analysis uses the categorization of the results of the whole method into six main failures, listed in Table 1.

Table 1 Code Fault type

\begin{tabular}{|c|c|}
\hline Code for fault & Fault type \\
\hline PD & Partial discharge \\
\hline D1 & Low energy discharges \\
\hline D2 & High energy discharges \\
\hline T1 & $\begin{array}{c}\text { Low Thermal faults not exceeding } 300^{\circ} \mathrm{C} \\
\text { temperature }\end{array}$ \\
\hline T2 & $\begin{array}{c}\text { Medium Thermal faults between } 300^{\circ} \mathrm{C} \text { to } 700^{\circ} \mathrm{C} \\
\text { temperature }\end{array}$ \\
\hline T3 & High Thermal faults above $700^{\circ} \mathrm{C}$ temperature \\
\hline
\end{tabular}

\section{A. Roger's Ratio Method}

The Rogers Ratio method diagnoses failures by taking the ranges of the gas ratios in mineral oil; Four gas ratios are required: $\mathrm{C}_{2} \mathrm{H}_{2}$ / $\mathrm{C}_{2} \mathrm{H}_{4}, \mathrm{C}_{2} \mathrm{H}_{6} / \mathrm{CH}_{4}, \mathrm{C}_{2} \mathrm{H}_{4} / \mathrm{C}_{2} \mathrm{H}_{6}$ and $\mathrm{CH}_{4} / \mathrm{H}_{2}$. Using these four gas ratios, diagnose faults such as normal aging, winding circuit currents, electrical faults, low energy discharge faults, and thermal faults in various areas (1500c-7000c) [9]. The main advantage of gas ratio analysis is "it is independent of the amount of oil involved and depends only on the proportions of the gases involved"

In this technique, four relationships are identified to diagnose the types of transformer failures. These relationships are structured as follows according to five main gases:

$\left[\mathrm{R}_{1} \mathrm{R}_{2} \mathrm{R}_{3} \mathrm{R}_{4}\right]=\left[\frac{\mathrm{C}_{2} \mathrm{H}_{2}}{\mathrm{C}_{2} \mathrm{H}_{4}} \frac{\mathrm{CH}_{4}}{\mathrm{H}_{2}} \frac{\mathrm{C}_{2} \mathrm{H}_{4}}{\mathrm{C}_{2} \mathrm{H}_{6}} \frac{\mathrm{C}_{2} \mathrm{H}_{6}}{\mathrm{CH}_{4}}\right]$

\begin{tabular}{|l|l|l|}
\hline \multicolumn{2}{|c|}{ Table 2 Fault type } \\
\hline Proposed fault type & IEC code & Rogers four ratios \\
\hline $\begin{array}{l}\text { No fault } \\
\text { undetermined fault }\end{array}$ & $\begin{array}{l}\text { Normal state (s.1) } \\
\text { No fault identification } \\
\text { (s.2) }\end{array}$ & $\begin{array}{l}\text { Normal state (s.1) } \\
\text { No fault } \\
\text { identification (s.2) }\end{array}$ \\
\hline PD & Low energy PD (s.3) & PD (s.3) \\
\hline D1 & high energy PD (s.4) & $\begin{array}{l}\text { Arching discharge } \\
\text { with low energy } \\
\text { (s.10) }\end{array}$ \\
\hline & $\begin{array}{l}\text { Low energy discharge } \\
(\mathrm{s} .5)\end{array}$ & $\begin{array}{l}\text { Continuous spark } \\
(\mathrm{s} .12) \\
\text { PD with tracking } \\
(\mathrm{s} .11)\end{array}$ \\
\hline D2 & $\begin{array}{l}\text { Arc with a high } \\
\text { energy density (s.11) }\end{array}$ \\
\hline T1 & $\begin{array}{l}\text { Low thermal fault }<150^{\circ} \\
(\mathrm{s} .7)\end{array}$ & $\begin{array}{l}\text { Thermal fault } \\
150^{\circ} \mathrm{C}(\mathrm{s} .4)\end{array}$ \\
\hline & $\begin{array}{l}\text { Thermal fault }(150- \\
\text { Thermal fault (150- } \\
\left.200^{\circ} \mathrm{C}\right)(\mathrm{s} .5)\end{array}$ \\
\hline
\end{tabular}

\begin{tabular}{|l|l|l|}
\hline & & $\begin{array}{l}\text { Thermal fault (200- } \\
\left.300^{\circ} \mathrm{C}\right)(\mathrm{s} .5)\end{array}$ \\
\hline T2 & $\begin{array}{l}\text { Medium thermal fault } \\
\left(300-700^{\circ} \mathrm{C}\right)(\mathrm{s} .9)\end{array}$ & $\begin{array}{l}\text { Thermal fault } \\
\text { (increases in overall } \\
\text { temperature in the } \\
\text { conductive part) (s.7) } \\
\text { thermal fault } \\
\text { (circulating current in } \\
\text { winding) (s.8) }\end{array}$ \\
\hline T3 & $\begin{array}{l}\text { High thermal fault } \\
>700^{\circ} \mathrm{C}(\mathrm{s} .10)\end{array}$ & $\begin{array}{l}\text { Thermal fault (core } \\
\text { and tank circulating } \\
\text { current overheated } \\
\text { joints)(s.9) }\end{array}$ \\
\hline
\end{tabular}

Table 2 shows the eight error states, which also include normal operation and the error-free state in the IEC code. The eight types of defects were organized to explain six types of defects. The state (see 3) refers to PD, the state (see 4) and (see 5) refers to $\mathrm{D} 1, \mathrm{D} 2$ is represented by the state (see 6), the states (see 7) and (p .8) are referred to the type of error in T1. The types of errors T2 and T3 are represented by the states (see 9) and (see 10).

The error types and error codes of the Rogers Four Ratio method are also shown in Table 1. The states (see 4), (see 5), and (see 6) have been combined to refer to a low thermal error (T1)., the states (p.7) and (p.8) have been merged to refer to the mean thermal error (T2) and the state (p.11) refers to the high energy discharge error (D2), state (s 3) refers to the PD error, the states (s.10), s.12) and (s.13) refer to the low energy discharge D1 and the state (s.9) refers to the high thermal error T3. In the Duval triangle method, the electrical-thermal error (DT) is divided between the errors D1 and D2 so that a comparison can be made with the other methods.

\section{B. Doernenburg Ratio Method}

This technique uses four different gas ratios such as $\mathrm{C} 2 \mathrm{H} 6$ / $\mathrm{C} 2 \mathrm{H} 2, \mathrm{CH} 4 / \mathrm{H} 2, \mathrm{C} 2 \mathrm{H} 2 / \mathrm{CH} 4$ and $\mathrm{C} 2 \mathrm{H} 2 / \mathrm{C} 2 \mathrm{H} 4$. Based on these gas velocity ranges, it diagnoses various fault conditions such as partial discharges, arcing and thermal failures with varying degrees of severity. This method is one of the oldest methods for detecting initial failures in transformers. To use this procedure, the first condition to be met is that at least one of the key gas concentrations $\left(\mathrm{H}_{2} ; \mathrm{CH}_{4} ; \mathrm{C}_{2} \mathrm{H}_{6} ; \mathrm{C}_{2} \mathrm{H}_{4} ; \mathrm{C}_{2} \mathrm{H}_{2}\right)$ exceeds twice the concentration limits (L1) indicated in Table 4.3 and that one of the other two gases exceed the limit value L1. Once this condition is met, the four typical gas ratios $\left(\mathrm{CH}_{4} / \mathrm{H}_{2}\right.$; $\mathrm{C}_{2} \mathrm{H}_{2} / \mathrm{C}_{2} \mathrm{H}_{4} ; \mathrm{C}_{2} \mathrm{H}_{2} / \mathrm{CH}_{4} ; \mathrm{C}_{2} \mathrm{H}_{6} / \mathrm{C}_{2} \mathrm{H}_{2}$ ) are used to investigate the types of errors according to Table 4.3. 
Table 3 concentration limits L1 of dissolved gases

\begin{tabular}{|l|l|l|l|l|l|l|}
\hline Dissolved gases & $\mathrm{H}_{2}$ & $\mathrm{CH}_{4}$ & $\mathrm{CO}$ & $\mathrm{C}_{2} \mathrm{H}_{2}$ & $\mathrm{C}_{2} \mathrm{H}_{4}$ & $\mathrm{C}_{2} \mathrm{H}_{6}$ \\
\hline $\begin{array}{l}\text { Concentration } \\
\text { limit L1 }\end{array}$ & 100 & 120 & 350 & 1 & 50 & 65 \\
\hline
\end{tabular}

Table 4 fault analysis based on Dornenberg ratio

\begin{tabular}{|l|l|l|l|l|}
\hline Case of error & $\mathrm{CH}_{4} / \mathrm{H}_{2}$ & $\mathrm{C}_{2} \mathrm{H}_{2} / \mathrm{C}_{2} \mathrm{H}_{4}$ & $\begin{array}{l}\mathrm{C}_{2} \mathrm{H}_{2} / \\
\mathrm{CH}_{4}\end{array}$ & $\begin{array}{l}\mathrm{C}_{2} \mathrm{H}_{6} / \\
\mathrm{C} 2 \mathrm{H} 2\end{array}$ \\
\hline $\begin{array}{l}\text { Thermal (low } \\
\text { decomposition }\end{array}$ & $>1$ & $>0.75$ & $<0.3$ & $>0.4$ \\
\hline $\begin{array}{l}\text { Corona partial } \\
\text { intensity } \\
\text { discharge } \\
\text { discharge) }\end{array}$ & Insignificant & $<0.3$ & $>0.4$ \\
\hline $\begin{array}{l}\text { Arcing (high } \\
\text { intensity partial } \\
\text { discharge) }\end{array}$ & $>0.1-<1$ & $<0.75$ & $>0.3$ & $<0.4$ \\
\hline
\end{tabular}

C. ANN

ANNs are information processing systems that simulate human behavior. The ANNs obtain information about the characteristics considered and learn from the input data, even if our model contains noise. The structure of the ANN consists of essential information processing units, which are neurons.

They are divided into several layers and linked together by defining weights. The synaptic weights show the interaction between each pair of neurons. These structures distribute information across neurons. The mapping of the input and the estimated responses of the output are calculated by combining several transfer functions. We can use the self-adaptive information shape recognition method to analyze the learning algorithms of artificial neural networks. The most commonly used calculation algorithm is the backward error propagation algorithm.

Neural networks can be divided into single-layer perception networks and multilayer perception networks (MLPs). The multilayer perceptual network comprises several layers of simple two-state sigmoid transfer functions with processing neurons interacting by applying weighted connections. A typical multilayer neural network consists of the input layer, the output layer, and the hidden layer. Multilayer perception (MLP) with the back-propagation learning algorithm is used in this study because many previous researchers have used this type of ANN and it is also a general function approximator.

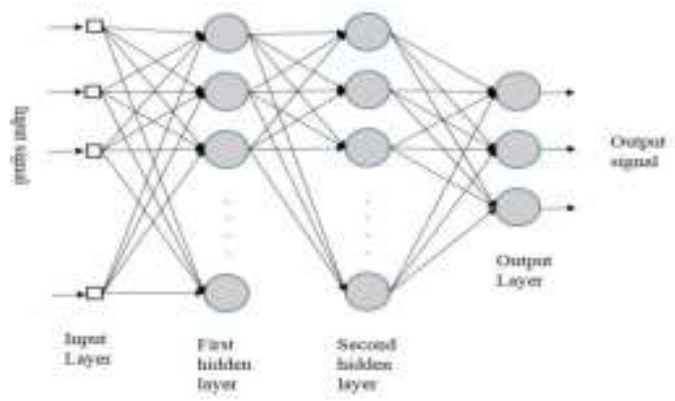

Fig. 2 Architectural Graph of an MLP Network with Two Hidden Layers.

The study of the connection among both input factors with output variables formed the foundation for the creation of ANN models. As illustrated in Fig. 2, the neural architecture consisting of 3 or even more layers, namely the $\mathrm{H}$. Input layer with output layer, and then hidden layer. The following is a description of that network's function:

$$
Y_{j}=f\left(\sum_{i} w_{i j} X_{i j}\right)
$$

$\mathrm{f}($.$) here is transfer function, and \mathrm{Yj}$ means output of that node $\mathrm{j}$. $\mathrm{Xij}$ here the input signal through node $\mathrm{i}$ at the lower layer to this node $\mathrm{j}$, While wij is just the weight of that link between node $\mathrm{j}$ with node $\mathrm{i}$ at the lower layer.

In DGA-based intelligent mistake detection, several researchers utilized neural network ideas. Prediction, segmentation, regression, and time series prediction these are all common applications to multiple layer of perceptron neural networks. In these neural networks, the training algorithm is much essential. The training algorithm changes the distortions as well as weight so this input-output mapping takes as little time as possible. That back propagation algorithm (BPN) was an earliest learning algorithm, also it is used to under supervision learning of a multiple layered neural-network with prediction. This same back-propagation of output-level unit error determines hidden layers unit errors, which is also the fundamental concept underlying the word back-propagation. 2 Back-propagation is used in a variety of learning methods. A steepest descent algorithm, often known as gradient descent algorithm, is perhaps the most widely used. The goal is to make that variation in weight proportional to a negative of derivatives of the observed error for every weight of the present model:

$\Delta_{p} w_{j}=-\gamma \frac{\partial E^{p}}{\partial w_{j}}$

The gradient descent technique, also the gradient descent method using adaptive learning method, as well as the LevenbergMarquardt method are all topology of that back-propagation learning algorithm described in this paper for the detection of 
transformer faults. Every arrangement takes as input concentration ratio ( $\mathrm{ppm}$ ) of following gases (Acetylene, Ethylene, Ethane, Hydrogen and Methane, i.e. R1 (C2H2Acetylene/ C2H4-Ethylene, R2 (CH4-Methane / H2-Hydrogen) and R3 (C2H4-Ethylene / C2H6-Ethane), and incorporates all kinds of mistakes within system learning variables.

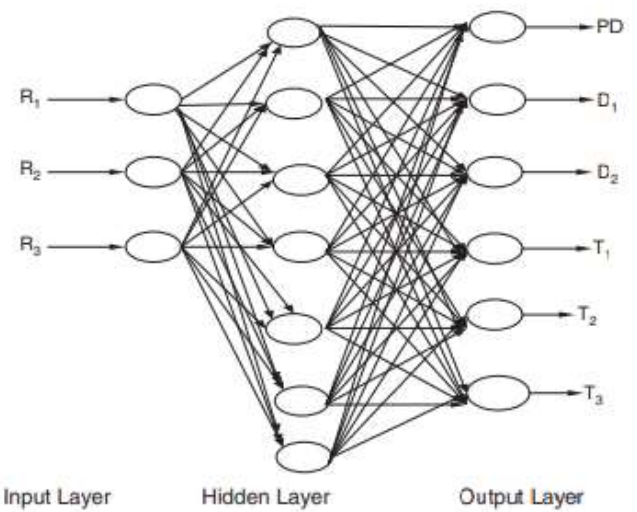

Fig. 3 Neural network back propagation algorithm for fault prediction

\section{RESULTS}

This chapter discusses the interpretation of three techniques for two designed data set values. The dataset is first selected for the preventive implementation of the techniques and its performance is examined with limited values of the available gas concentrations. Subsequently, the study was extended to a greater amount of data, then the effectiveness of the two methods was examined and compared with that of the learning method, among all the classic diagnostic techniques, the Rogers ratio method, the Doernenburg ratio. It also describes the representation of the zone for all types of errors and their software implementation in MATLAB.

\begin{tabular}{|c|c|c|c|c|c|c|}
\hline \multicolumn{7}{|c|}{ Table 5 Selection of Data set-1 with relatively less data } \\
\hline Sno. & $\mathrm{H}_{2}$ & $\mathrm{CH}_{4}$ & $\mathrm{C}_{2} \mathrm{H}_{6}$ & $\mathrm{C}_{2} \mathrm{H}_{4}$ & $\mathrm{C}_{2} \mathrm{H}_{2}$ & ACT \\
\hline 1 & 1651 & 90 & 33 & 45 & 2 & 1 \\
\hline 2 & 234.5 & 30.28 & 6.11 & 47.69 & 175.88 & 2 \\
\hline 3 & 18.34 & 16.26 & 3.38 & 17.95 & 16.42 & 3 \\
\hline 4 & 235.46 & 333.59 & 177.52 & 1201.85 & 148.87 & 3 \\
\hline 5 & 505.57 & 475.35 & 242.3 & 524.45 & 3.29 & 4 \\
\hline 6 & 36 & 30 & 10 & 93 & 7.1 & 6 \\
\hline
\end{tabular}

\section{A. Rogers ratio method for minimum data (Data Set-1):}

The Rogers ratio method compares the quantities of different key gases by dividing them against each other. This gives a ratio of the amount of one key gas to another. Report methods are only valid when there is a significant amount of gas used in the report.

\begin{tabular}{|l|c|c|c|c|c|c|c|c|c|c|}
\hline \multicolumn{10}{|c|}{ Table 6 Types of fault prediction using roger's ratio method in matlab } \\
\hline & $\begin{array}{l}\text { AC } \\
\text { T }\end{array}$ & $\begin{array}{l}\text { P } \\
\text { D }\end{array}$ & $\begin{array}{l}\text { D } \\
1\end{array}$ & $\begin{array}{l}\text { D } \\
2\end{array}$ & T1 & $\begin{array}{c}\text { T } \\
2\end{array}$ & $\begin{array}{l}\text { T } \\
3\end{array}$ & $\begin{array}{c}\text { U } \\
\text { D }\end{array}$ & $\begin{array}{l}\text { N } \\
\text { F }\end{array}$ & $\begin{array}{l}\text { Accurac } \\
\text { y }\end{array}$ \\
\hline $\begin{array}{l}\text { P } \\
\text { D }\end{array}$ & 1 & 0 & 0 & 0 & 0 & 0 & 0 & 1 & 0 & 0 \\
\hline D1 & 1 & 0 & 0 & 1 & 0 & 0 & 0 & 0 & 0 & 0 \\
\hline D2 & 2 & 0 & 0 & 1 & 0 & 0 & 1 & 0 & 0 & 50 \\
\hline T1 & 1 & 0 & 0 & 0 & 0 & 1 & 0 & 0 & 0 & 0 \\
\hline T2 & 0 & 0 & 0 & 0 & 0 & 0 & 0 & 0 & 0 & NAN \\
\hline T3 & 1 & 0 & 0 & 0 & 0 & 0 & 0 & 1 & 0 & 0 \\
\hline $\begin{array}{l}\text { Al } \\
1\end{array}$ & 6 & 0 & 0 & 2 & 0 & 1 & 1 & 2 & 0 & 16.6667 \\
\hline
\end{tabular}

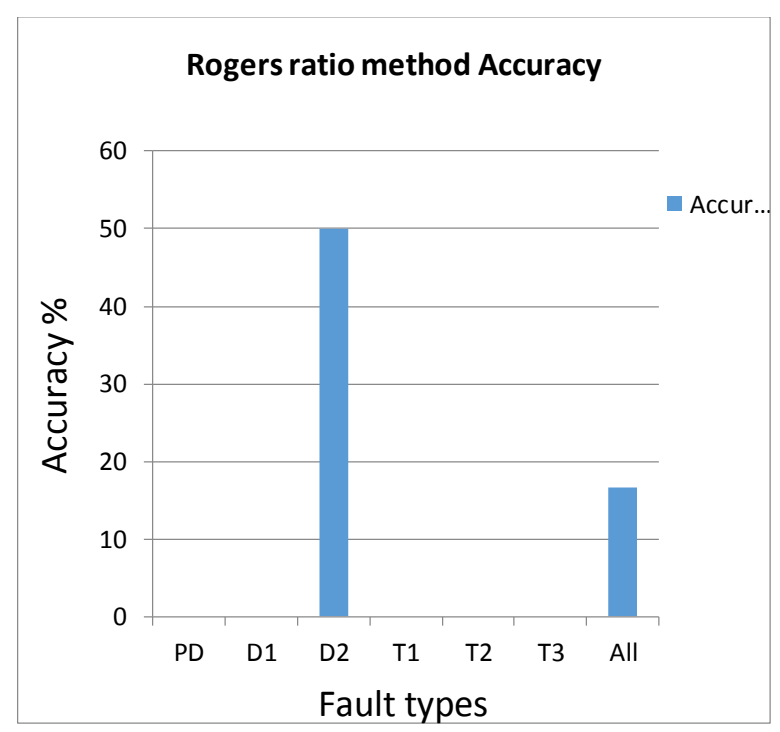

Fig. 3 Accuracy analysis graph of Roger's Ratio method during analysis of data set-1

The results of the Rogers ratio method were examined and then compared to the actual error, after which the accuracy of the Rogers ratio method for each error determination is examined and plotted on a graph. The analysis showed that the Rogers ratio method was best suited for detecting fault type D2, which is a high thermal fault in the transformer, with a single input phrase for analysis. Finally, the efficiency of the method for determining all types of errors for the dataset was found to be $16.66 \%$

\section{B. Doernenburg Ratio for minimum data (Data Set-1):}


Using gas velocity ranges, it diagnoses various fault conditions such as partial discharges, arcing and thermal failures of varying degrees of severity. The method is first used to process less gas data than input into the Matlab script to examine its performance under this condition.

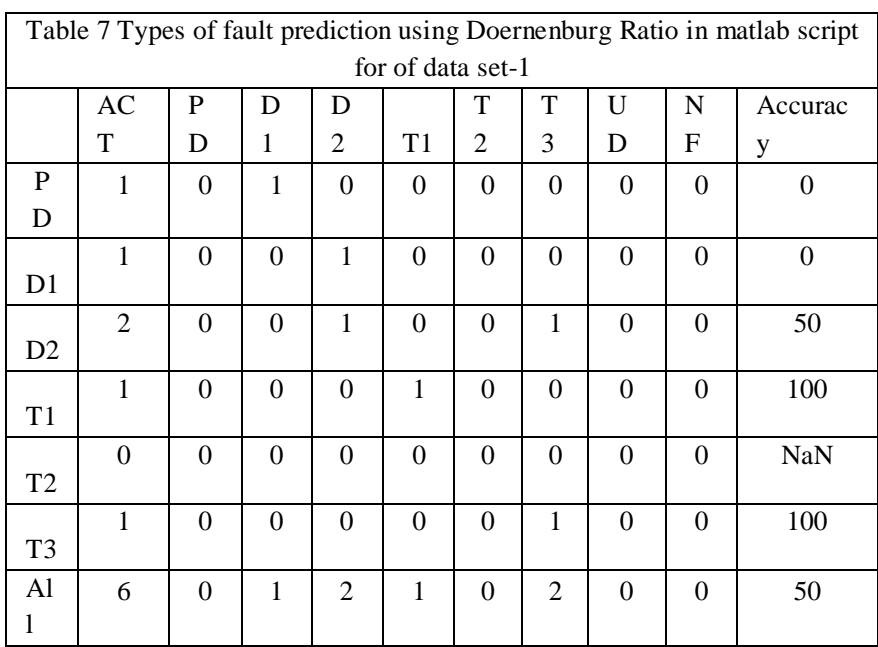

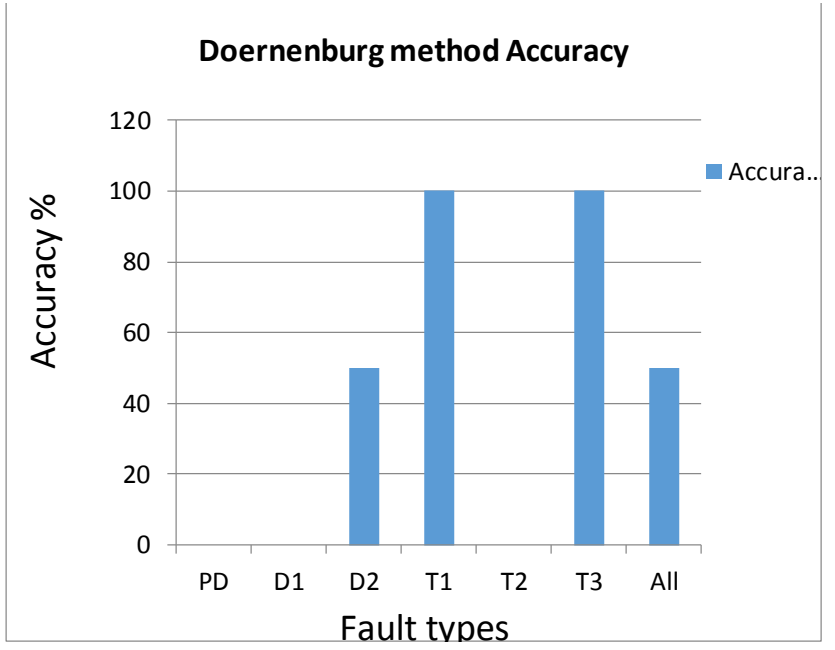

Fig. 4 Accuracy analysis graph of Doernenburg Ratio method during analysis of data set-1

\begin{tabular}{|c|c|c|c|c|c|c|}
\hline \multicolumn{7}{|c|}{ Table 8 Selection of Data set-2 with large gas concentration as } \\
input \\
\hline Sno. & $\mathrm{H}_{2}$ & $\mathrm{CH}_{4}$ & $\mathrm{C}_{2} \mathrm{H}_{6}$ & $\mathrm{C}_{2} \mathrm{H}_{4}$ & $\mathrm{C}_{2} \mathrm{H}_{2}$ & ACT \\
\hline 1 & 2091 & 149 & 20 & 3 & 0.001 & 1 \\
\hline 2 & 8200 & 3790 & 250 & 4620 & 277 & 3 \\
\hline 3 & 75 & 15 & 7 & 14 & 250 & 3 \\
\hline 4 & 530 & 345 & 85 & 266 & 21 & 3 \\
\hline 5 & 60 & 5 & 2 & 21 & 32 & 3 \\
\hline 6 & 5900 & 1500 & 68 & 1200 & 800 & 3 \\
\hline 7 & 1 & 27 & 49 & 4 & 1 & 4 \\
\hline
\end{tabular}

\begin{tabular}{|c|c|c|c|c|c|c|}
\hline 8 & 14 & 14 & 124 & 7 & 1 & 4 \\
\hline 9 & 3420 & 7870 & 1500 & 6990 & 33 & 6 \\
\hline 10 & 19.3 & 103 & 159 & 19 & 0.6 & 6 \\
\hline 11 & 27 & 30 & 23 & 2.4 & 0.1 & 4 \\
\hline 12 & 23 & 63 & 54 & 10 & 0.3 & 2 \\
\hline 13 & 21 & 34 & 5 & 47 & 62 & 3 \\
\hline 14 & 160 & 130 & 33 & 96 & 0.1 & 5 \\
\hline 15 & 180 & 175 & 75 & 50 & 4 & 5 \\
\hline 16 & 345 & 112.3 & 27.5 & 51.5 & 58.8 & 2 \\
\hline 17 & 30.4 & 117 & 44.2 & 138 & 0.1 & 5 \\
\hline 18 & 181 & 262 & 41 & 28 & 0.001 & 4 \\
\hline 19 & 173 & 334 & 172 & 812.5 & 37.7 & 6 \\
\hline 20 & 127 & 107 & 11 & 154 & 224 & 3 \\
\hline 21 & 60 & 40 & 6.9 & 110 & 70 & 3 \\
\hline 22 & 220 & 340 & 42 & 480 & 14 & 6 \\
\hline 23 & 170 & 320 & 53 & 520 & 3.2 & 6 \\
\hline 24 & 27 & 90 & 42 & 63 & 0.2 & 5 \\
\hline 25 & 56 & 286 & 96 & 928 & 7 & 6 \\
\hline 26 & 200 & 48 & 14 & 117 & 131 & 3 \\
\hline 27 & 78 & 161 & 86 & 353 & 10 & 6 \\
\hline 28 & 32.4 & 5.5 & 1.4 & 12.6 & 13.2 & 3 \\
\hline 29 & 980 & 73 & 58 & 12 & 0.001 & 1 \\
\hline 30 & 160 & 130 & 33 & 96 & 0.001 & 4 \\
\hline 31 & 650 & 53 & 35 & 20 & 0.001 & 1 \\
\hline 32 & 95 & 110 & 160 & 50 & 0.001 & 4 \\
\hline 33 & 300 & 490 & 180 & 360 & 95 & 5 \\
\hline 34 & 200 & 700 & 250 & 740 & 1 & 5 \\
\hline 35 & 625 & 130 & 47 & 2 & 0.0001 & 4 \\
\hline 36 & 56 & 61 & 75 & 32 & 31 & 1 \\
\hline 37 & 1651 & 90 & 33 & 45 & 2 & 1 \\
\hline 38 & 234.5 & 30.28 & 6.11 & 47.69 & 175.88 & 2 \\
\hline 39 & 18.34 & 16.26 & 3.38 & 17.95 & 16.42 & 3 \\
\hline 40 & 235.46 & 333.59 & 177.52 & 1201.85 & 148.87 & 3 \\
\hline 41 & 505.57 & 475.35 & 242.3 & 524.45 & 3.29 & 4 \\
\hline 42 & 36 & 30 & 10 & 93 & 7.1 & 6 \\
\hline
\end{tabular}

\section{Rogers Ratio Method implementation with data set-2}

The early identification of gas dissolved into transformer oil, due to the result of various electrical also with thermal loads avoids transformer failure and therefore ensures the electrical network's continuance of operation. The technique of dissolved gas analysis (DGA) was commonly used for identifying forthcoming failures in oil bath power transformer. As a result, 
diagnosing emerging problems is feasible using this technique in software MATLAB. The Rogers ratio method's MATLAB outcome is shown in the table.

The analysis of the results shows all relevant gas key number ranges and their code and mineral oil status.

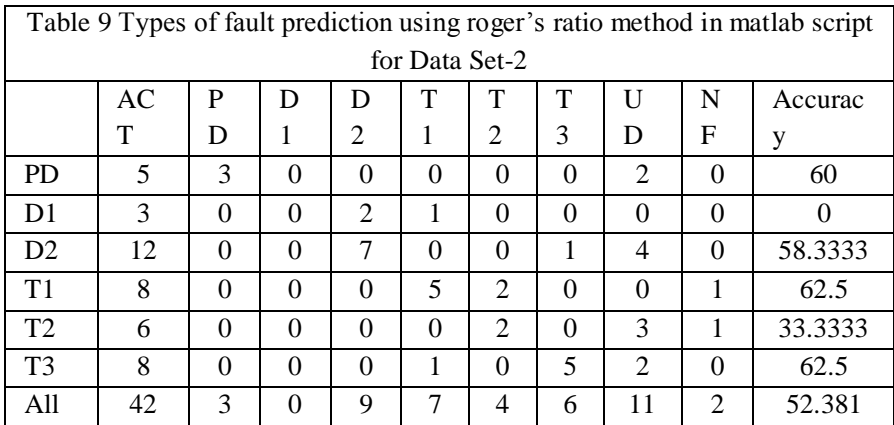

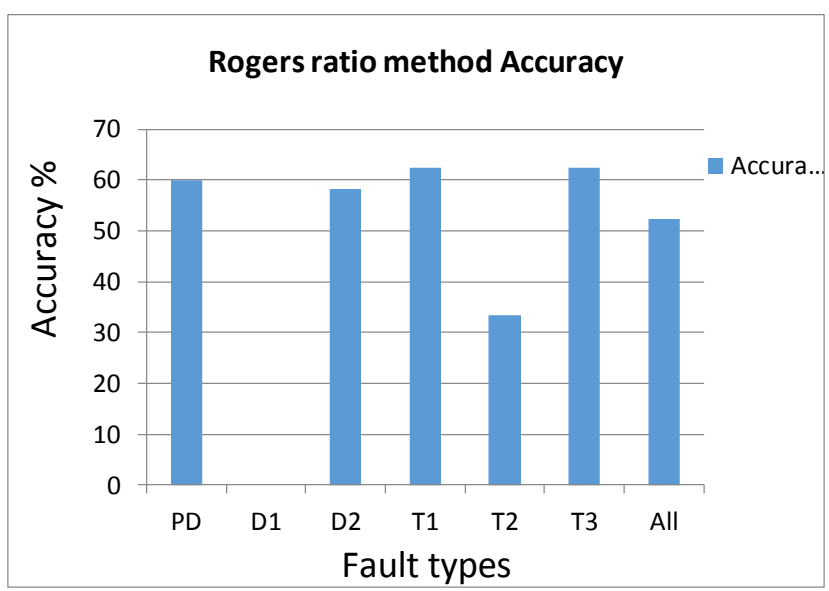

Fig. 5 Accuracy analysis graph of Rogers ratio method during analysis for data set-2

The results of the Rogers ratio method when used in MATLAB demonstrated its percentage accuracy in determining various types of errors. The dataset with 42 samples with the Roger ratio method of the DGA analysis was used for dissolved gas analysis. The Rogers ratio results were reviewed and then compared to the actual error, after which the accuracy of the Rogers ratio technique for each error determination is examined and graphed. Analysis showed that Roger's ratio method efficiency in detecting $\mathrm{T} 1$ and $\mathrm{T} 3$ types was maximal and was $62.5 \%$. The efficiency of this method for determining the type of $\mathrm{T} 2$ error was also $33.3 \%$. Finally, the effectiveness and efficiency of the Rogers ratio method in determining all types of errors for the entire data set was found to be $52.38 \%$.

\section{Doernenburg Ratio implementation with data set-2}

Using gas velocity ranges, it diagnoses various fault conditions such as partial discharges, arcing and thermal failures of varying degrees of severity. Therefore, by implementing this method in MATLAB, incipient errors can be diagnosed in a window. The method is considered for implementation in the analysis of the selected data sets, so its accuracy is calculated in the determination of various errors. The comparative study was carried out in the book. The analysis was also more effective in formulating various types of error hypotheses.

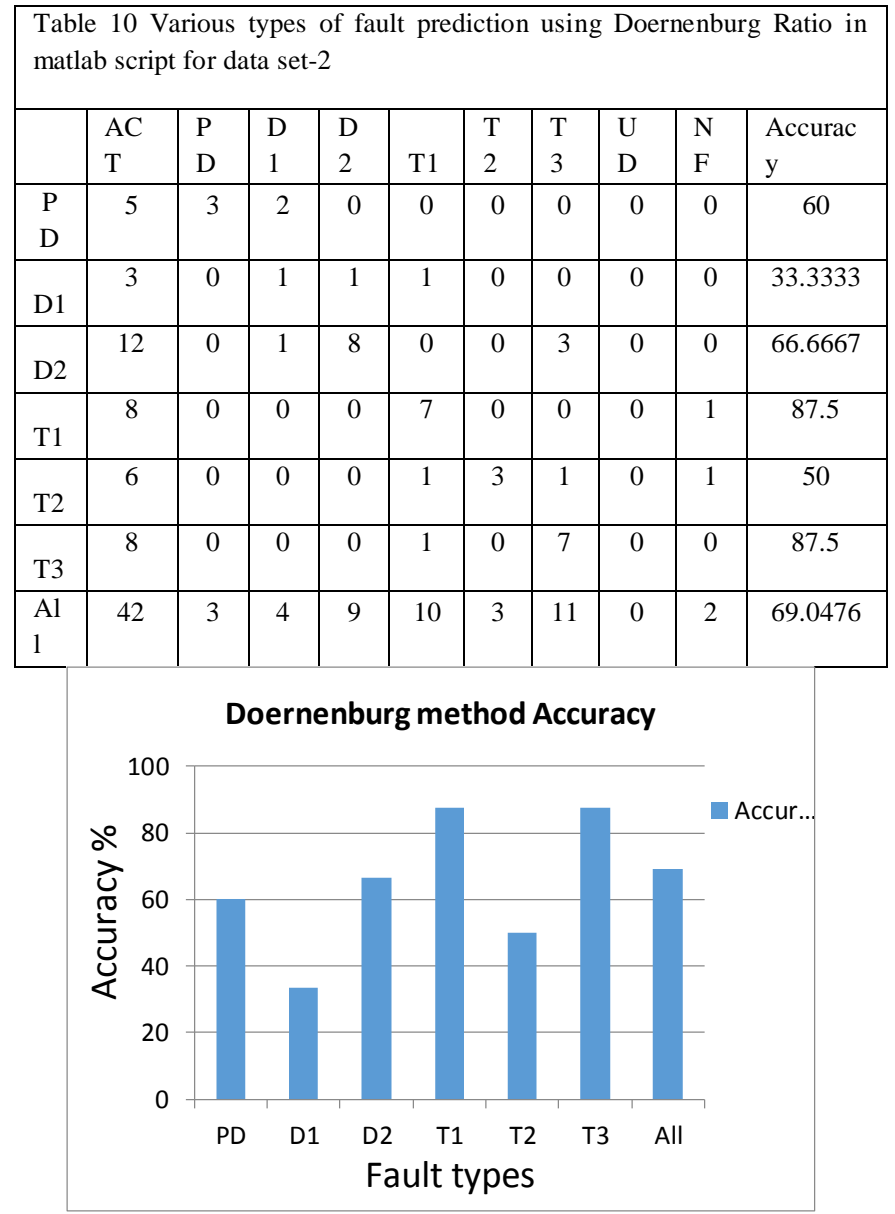

Fig. 6 Accuracy analysis graph of Doernenburg Ratio method during analysis for data set-2

The results of the Doernenburg ratio method were examined and then compared to the actual error, after which the accuracy of the Doernenburg ratio method for each error determination is examined and graphed. The analysis showed that the efficiency of the Doernenburg ratio method in recognizing $\mathrm{T} 1$ and $\mathrm{T} 3$ types was maximal and was $87.5 \%$. The efficiency of this method for determining the type of D1 error was also the lowest at 33.33\%. Finally, the effectiveness and efficiency of the Doernenburg ratio method in determining all types of errors for the entire data set was found to be $69.04 \%$. 


\section{E. ANN Implementation with data set-2}

Table 11 Various types of fault prediction using ANN in matlab script for data set-2

\begin{tabular}{|c|c|c|c|c|c|c|c|c|c|c|}
\hline & $\begin{array}{l}\mathrm{AC} \\
\mathrm{T}\end{array}$ & $\begin{array}{c}\mathrm{P} \\
\mathrm{D}\end{array}$ & $\begin{array}{l}\mathrm{D} \\
1\end{array}$ & $\begin{array}{l}\mathrm{D} \\
2\end{array}$ & $\mathrm{~T} 1$ & $\begin{array}{c}\mathrm{T} \\
\mathrm{D}\end{array}$ & $\begin{array}{l}\mathrm{T} \\
3\end{array}$ & $\begin{array}{l}\mathrm{U} \\
\mathrm{D}\end{array}$ & $\begin{array}{l}\mathrm{N} \\
\mathrm{F}\end{array}$ & $\begin{array}{l}\text { Accurac } \\
\mathrm{y}\end{array}$ \\
\hline $\mathrm{P}$ & 5 & 3 & 0 & 1 & 0 & 0 & 0 & 1 & 0 & 60 \\
$\mathrm{D} 1$ & 3 & 0 & 2 & 0 & 1 & 0 & 0 & 0 & 0 & 66.6667 \\
$\mathrm{D} 2$ & 12 & 1 & 0 & 11 & 0 & 0 & 0 & 0 & 0 & 91.6667 \\
\hline $\mathrm{T} 1$ & 8 & 0 & 0 & 0 & 7 & 0 & 0 & 1 & 0 & 87.5 \\
\hline $\mathrm{T} 2$ & 6 & 0 & 0 & 0 & 3 & 2 & 0 & 1 & 0 & 33.3333 \\
\hline $\mathrm{T} 3$ & 8 & 0 & 0 & 0 & 1 & 0 & 6 & 1 & 0 & 75 \\
\hline $\begin{array}{l}\mathrm{A} 1 \\
1\end{array}$ & 42 & 4 & 2 & 12 & 12 & 2 & 6 & 4 & 0 & 73.8095 \\
\hline
\end{tabular}

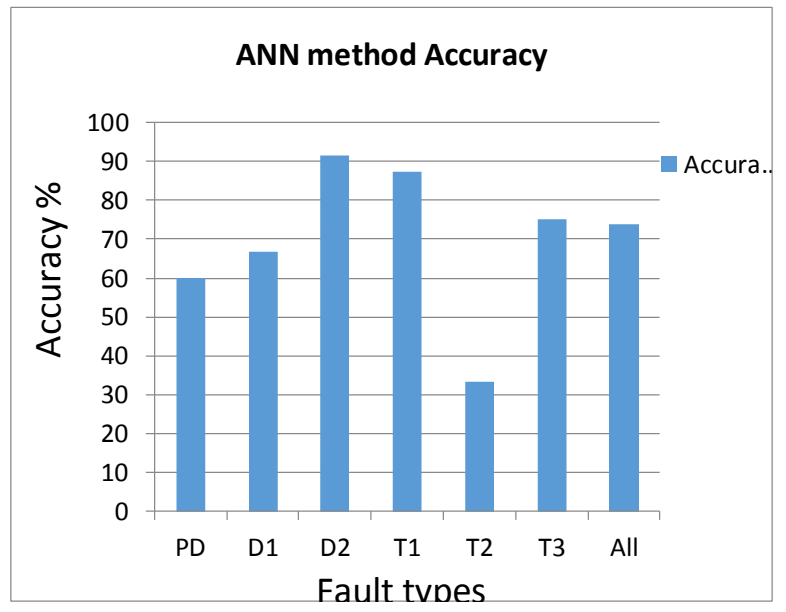

Fig. 7 Accuracy analysis graph of ANN method during analysis

The results of the ANN method were examined and then compared to the actual error, after which the accuracy of the ANN method technique is examined and graphed for each error determination. The analysis showed that the efficiency of the ANN method in detecting type D2 was maximal and was $91.6 \%$. The efficiency of this method for determining the type of $\mathrm{T} 2$ error was also lower with $33.33 \%$. Finally, the effectiveness and efficiency of the Doernenburg ratio method in determining all types of errors for the entire data set was found to be $73.80 \%$.

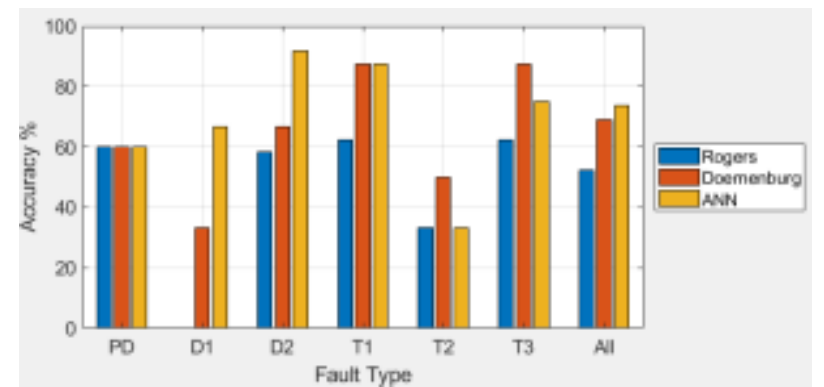

Fig. 8 Comparative Graph of all methods for each fault in matlab analysis of data set 2

\section{CONCLUSION}

Dissolved Gas Analysis (DGA) is the most proven precision method for assessing the condition of power transformers. This provides information in advance about the degree of degradation of mineral oil and dissolved gases generated in mineral oil and the concentration of dissolved gases by gas chromatography. The concentration of the key gases identified by different conventional methods results in different conditions for the same sampling unit. In this work, it was considered the point of combining the line discussed above and the construction of the three diagnostic methods for better accuracy of results for diagnosing incipient errors. The analysis showed that the efficiency in determining the total error is shown in Figure.

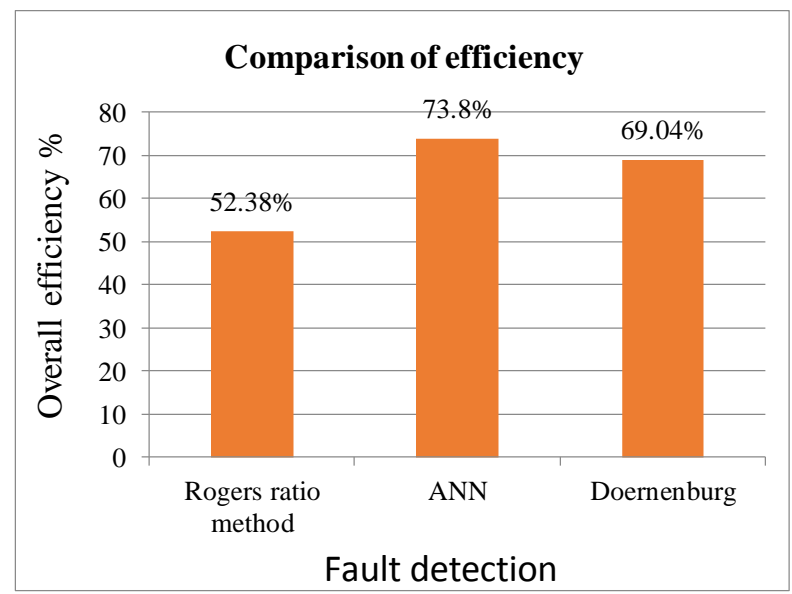

Fig. 9 Comparison Efficiency

This technique utilizes the learning capacity of that artificial neural network has been shown to be more efficient in detecting different mistakes. The overall error detection accuracy of such gas neural network study was found to be 73.8 percent. 


\section{REFERENCES}

[1] S. S. M. Ghoneim and I. B. M. Taha, "A new approach of DGA interpretation technique for transformer fault diagnosis," International Journal of Electrical Power and Energy Systems, vol. 81, pp. 265-274, 2016.

[2] T. Kari, W. Gao, D. Zhao et al., "An integrated method of ANFIS and Dempster-Shafer theory for fault diagnosis of power transformer," IEEE Transactions on Dielectrics and Electrical Insulation, vol. 25, no. 1, pp. 360-371, 2018.

[3] M. Arshad, S. Islam, and A. Khaliq, "Fuzzy logic approach in power transformers management and decision making," IEEE Transactions on Dielectrics and Electrical Insulation, vol. 21, no. 5, pp. 2343-2354, 2014.

[4] O. E. Gouda, S. M. Saleh, and S. H. El-hoshy, "Power transformer incipient faults diagnosis based on dissolved gas analysis," Indonesian Journal of Electrical Engineering and Computer Science, vol. 1, no. 1, pp. 10-16, 2016.

[5] G. K. Irungu, A. O. Akumu, and J. L. Munda, "Application of fuzzy logic and evidential reasoning methodologies in transformer insulation stress assessment," IEEE Transactions on Dielectrics and Electrical Insulation, vol. 23, no. 3, pp. 1444-1452, 2016.

[6] N. A. Bakar and A. Abu-Siada, "Fuzzy logic approach for transformer remnant life prediction and asset management decision," IEEE Transactions on Dielectrics and Electrical Insulation, vol. 23, no. 5, pp. 3199-3208, 2016.

[7] Edwell T. Mharakurwa, G. N. Nyakoe "Power Transformer Fault Severity Estimation Based on Dissolved Gas Analysis and Energy of Fault Formation Technique" Journal of Electrical and Computer Engineering / 2019.

[8] N.C. Joshi, Y.R. Sood "Transformer Internal Winding Faults Diagnosis Methods: A Review" MIT International Journal of Electrical and Instrumentation Engineering, Vol. 2, No. 2, Aug. 2012, pp. (77-81).

[9] Yan Wang, Liguo Zhang "A Combined Fault Diagnosis Method for Power Transformer in Big Data Environment" Mathematical Problems in Engineering / 2017

[10] Xue Wang, Tao Han "Transformer Fault Diagnosis Based on Stacking Ensemble Learning" https://doi.org/10.1002/tee.23247, 02 October 2020 